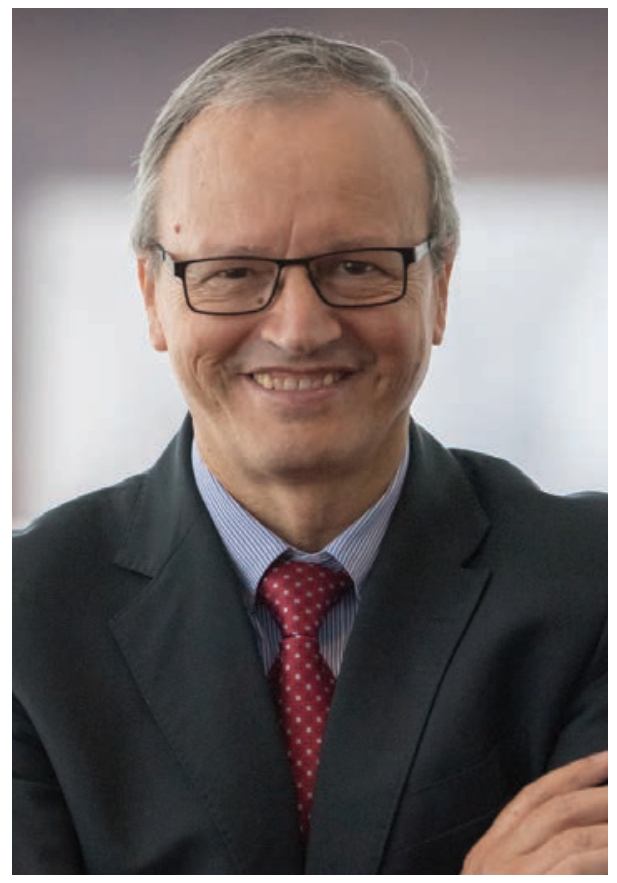

\title{
Envelhecimento e Bioética
}

\section{Aging and Bioethics}

\author{
Alberto Vieira, $\mathrm{MD}^{1}$
}

No presente número da Gazeta Médica são publicados dois artigos ligados à problemática do envelhecimento na saúde, um original - Estudo do processamento auditivo central em pessoas idosas de um centro de dia: Resultados preliminares, e outro de revisão - O envelhecimento pulmonar e as suas alterações imagiológicas.

A este propósito, este editorial pretende ser um convite à reflexão sobre envelhecimento e bioética.

A demografia e a epidemiologia demonstram o aumento crescente de idosos devido ao acelerado progresso biotecnológico e à melhoria das condições de vida. No entanto, há evidências de que o envelhecimento torna o organismo mais suscetível a doenças.

Sabendo que Portugal, de acordo com dados de 2015 do Eurostat, é o quarto país da União Europeia com maior percentagem de pessoas idosas, apenas ultrapassado pela Grécia, Alemanha e Itália, entre os 28 países membros, este problema do envelhecimento e as suas consequências médicas e bioéticas, bem como sociológicas e económicas são de relevante e crescente importância.

De facto, o aumento da população com 80 ou mais anos, tem sido significativa nas últimas décadas, verificando-se de acordo com dados oficiais da PORDATA de 2015, que esta faixa da população representava 1,43\% da população residente em Portugal em 1971, passando a representar 5,84\% em 2015.

Confirmando esta profunda transformação demográfica caracterizada, entre outros aspetos, pelo aumento da longevidade e da população idosa, verificamos que em 2017 o índice de longevidade no nosso país era de 29,2\%, ou seja, o dobro relativamente ao observado em 1960 (14,5\%), segundo dados do Eurostat-PORDATA.

O envelhecimento individual é um processo condicionado por fatores biológicos, sociais, económicos, culturais, ambientais e históricos, podendo ser definido como um processo progressivo de mudança biopsicossocial da pessoa durante todo o ciclo de vida (Organização Mundial de Saúde - OMS). 
Por sua vez, o conceito de "envelhecimento saudável" refere-se ao processo de desenvolvimento e manutenção da capacidade funcional, que contribui para o bem-estar das pessoas idosas, sendo a capacidade funcional o resultado da interação das capacidades físicas e mentais intrínsecas da pessoa com o meio (OMS).

Viver mais, também significa estar mais exposto a riscos, como a vulnerabilidade do estado de saúde, o isolamento social e pessoal, bem como a dependência física, mental e também económica.

No mundo, cerca de 23\% da carga global da doença é atribuível a condições que afetam pessoas com 60 ou mais anos. As principais condições que contribuem para esta excessiva carga global da doença são as doenças crónicas não transmissíveis, como as doenças cardiovasculares, alterações metabólicas como a diabetes, as neoplasias malignas, as doenças respiratórias crónicas, as doenças músculo-esqueléticas (como a artrose e a osteoporose), os distúrbios neurológicos e mentais, como a demência e a depressão (OMS).

O aumento da sobrevivência na presença destas doenças também resulta na perda de funcionalidade em idades mais avançadas.

As doenças crónicas não transmissíveis são responsáveis, segundo dados da Direção Geral de Saúde (DGS) de 2015, por $88 \%$ dos anos de vida vividos com incapacidades em Portugal, com destaque para as doenças músculo-esqueléticas (30,5\%) e as perturbações mentais e do comportamento (20,5\%).

Considerando que o envelhecimento se inicia logo após o nascimento e se prolonga por toda a existência e que as determinantes para o envelhecimento ativo exercem a sua influência durante toda a vida, as respostas da sociedade para o envelhecimento da população devem passar pelas várias fases do ciclo de vida (OMS).

As taxas de doença cardiovascular, respiratória, artropatias e doenças mentais refletem geralmente o sucesso ou a falência na prevenção das doenças referidas.

Nas últimas décadas, a investigação médica e biotecnológica conduziram à maior precocidade e precisão no diagnóstico, mas também ao desenvolvimento de novas terapêuticas, nomeadamente antibióticos e drogas antivirais e tratamentos inovadores em oncologia, bem como desenvolvimento de técnicas cirúrgicas salvadoras de muitas vidas como por exemplo a cirurgia coronária.

No entanto, todos estes ganhos em longevidade e melhoria dos indicadores de saúde em geral resultam de grandes investimentos biotecnológicos cada vez mais diferenciados e mais caros.

Também por este facto a população idosa encara por vezes a discriminação arbitrária não só social, mas também da comunidade médica, tornando o ageísmo um fenómeno mais lato e discriminatório como acontece quando o recrutamento para um ensaio clínico potencialmente salvador da vida é limitado pela idade do doente, ou excluído de uma terapêutica inovadora, mas cara, de uma forma arbitrária pela mesma razão.

Esta atitude pode ser vista como injusta para com as pessoas mais velhas, que, em princípio, por terem vivido muito, teriam mais experiência e sabedoria para aperfeiçoar a construção da comunidade onde estão inseridos. Esta era a perceção de Cícero em "De Senectute", obra em que considera a velhice como a presença do passado no presente, representando os idosos uma mais-valia como colaboradores competentes para tornar a sociedade mais justa e homogénea.

A modernidade, entretanto, tornou o passado território de pouco valor. Sob o influxo dos frequentes avanços tecnológicos da modernidade o 'novo' ganhou status especial, ultrapassando e esquecendo a reverência e o respeito tradicionalmente conferidos à sabedoria acumulada pelas pessoas idosas. Nessas condições, os idosos perdem prestígio e influência nas relações institucionais e por vezes apenas são merecedores de respeito se não se transformarem em peso demasiado oneroso para o equilíbrio financeiro da gestão pública dos recursos destinados à saúde. 